\title{
LETTERS
}

\section{The authors respond to "Underlying maternal infection likely cause of study findings"}

We thank Dr. Elwood and Dr. Money ${ }^{1}$ for their letter to the editor on our CMAJ article on the risk of spontaneous abortion associated with use of antibiotics during pregnancy. ${ }^{2}$ We agree that maternal infection may pose a risk to the developing fetus and the mother as stated in our introduction. Therefore, the use of appropriate antibiotics during pregnancy is warranted.

However, we strongly disagree that we underemphasized the potential limitations of our study. We clearly stated that confounding by infection severity was a potential limitation, and thus had performed multiple sensitivity analyses to quantify the extent of this bias if present. Indeed, we did several analyses to disentangle the effect of antibiotics from those of the underlying infection.

First, we used two comparator groups that included penicillins or cephalosporin users as reference categories, which had overlapping indications with other antibiotics users. ${ }^{3,4}$ Second, we conducted sensitivity analyses using an active comparator group (penicillins) within a subpopulation of pregnancies having the same type of infection (urinary tract infection and respiratory tract infection). Third, we adjusted for several documented proxies of infection severity such as prior exposure to antibiotics (which is a strong predictor of antibiotic resistance that may result in complicated infections), comorbidities (diabetes is also a well-known risk factor of complicated infection), hospital-based diagnosis of maternal infections and prior admissions to hospital. ${ }^{5-7}$

These secondary analyses provided results that were consistent with the main analysis, which was reassuring. Nevertheless, we still acknowledged that residual confounding by indication could not be ruled out completely.

Our findings and interpretations are in line with the comments by Dr. Money and Dr. Elmwood, given that they highlight the importance of treating bacterial infections during pregnancy with the safest antibiotics for both mother and fetus, when possible.

\section{Anick Bérard PhD}

Professor, Research Center, Centre hospitalier universitaire (CHU) SainteJustine; Researcher, Faculty of Pharmacy, Université de Montréal, Montréal, Que.

\section{Flory T. Muanda MD}

PhD student, Research Center, Centre hospitalier universitaire (CHU) SainteJustine; PhD student, Faculty of Pharmacy, Université de Montréal, Montréal, Que.

\section{Odile Sheehy MSc}

Research Coordinator, Research Center, Centre hospitalier universitaire (CHU)

Sainte-Justine, Montréal, Que.

Cite as: CMAJ 2017 July 10;189:E919. doi: $10.1503 / \mathrm{cmaj} .733254$

\section{References}

1. Elwood C, Money D. Underlying maternal infection likely cause of study findings [letter]. CMAJ 2017;189:E918.

2. Muanda FT, Sheehy O, Bérard A. Use of antibiotics during pregnancy and risk of spontaneous abortion. CMAJ 2017;189:E625-33.

3. Pneumonie acquise en communauté chez l'adulte. Québec (QC): Conseil du médicament; 2009. Available: https://www.inesss.qc.ca/fileadmin/doc/ CDM/UsageOptimal/Guides-seriel/CdM-Antibio1 -Pneumonie-Adulte-fr.pdf (accessed 2017 June 1).

4. Infections urinaires chez l'adulte. Québec (QC): Conseil du médicament; 2009. Available: https://www. inesss.qc.ca/fileadmin/doc/CDM/UsageOptimal/ Guides-seriel/CdM-Antibio1-InfectionsUrinaires -Adultes-fr.pdf (accessed 2017 June 1).

5. Hillier S, Roberts Z, Dunstan F, et al. Prior antibiotics and risk of antibiotic-resistant communityacquired urinary tract infection: a case-control study. J Antimicrob Chemother 2007;60:92-9.

6. Mazzulli T. Diagnosis and management of simple and complicated urinary tract infections (UTIS). Can J Urol 2012;19(Suppl 1):42-8.

7. Hertz FB, Schønning K, Rasmussen SC, et al. Epidemiological factors associated with ESBL- and non ESBL-producing $E$. coli causing urinary tract infection in general practice. Infect Dis (Lond) 2016;48:241-5.

Competing interests: Anick Bérard is a consultant for plaintiffs in litigations involving antidepressants and birth defects. No other competing interests were declared. 